\title{
A Goal Programming Approach for Green Supply Chain Network Optimization
}

\author{
Hao Yu, Wei Deng Solvang, Bjørn Solvang \\ Faculty of Engineering Science and Technology \\ UiT-The Arctic University of Norway \\ Narvik, Norway \\ e-mail: hao.yu@uit.no,wei.d.solvang@uit.no,bjorn.solvang@uit.no
}

\begin{abstract}
Green supply chain management has been focused by both academicians and practitioners in recent years due to the increased public awareness on environmental problems and sustainable development. In this paper, a decision aided model for green supply chain network design and optimization is proposed to justify both economic and environmental performance in an optimal fashion. The model is formulated as a bi-objective goal programming model aiming to balance supply chain cost and $\mathrm{CO}_{2}$ emission, which are usually conflict with each other. The model is validated through a numerical experiment, and discussion and analysis are also given based upon the computational result. The result provides managerial insights for companies in the supply chain, and it has been proved to be an effective tool for decision-making in strategic level of supply management. In general, more investment has to be spent for reducing the $\mathrm{CO}_{2}$ emission in a supply chain, and the result of sensitivity analysis presents the cost effectiveness in achieving the environmental goal.
\end{abstract}

Keywords-Goal programming; multi-objective programming; mixed integer programming; green supply chain management; optimization; network design; operational research; $\mathrm{CO}_{2}$ emission; carbon emission

\section{INTRODUCTION}

Supply chain and logistics activities are some of the most important fundamental components for supporting today's booming economy. The rapid growth in the volume of goods production and transportation all over the world not only benefits the economic development and globalization, but also leads to more influence on the environment [1]. In recent years, the environmental pollution accompanied with economic development and increased supply chain activities has been heavily focused by the public due to the increased awareness of sustainable development [2]. Green supply chain management or green logistics has been considered as one of the most effective tools for companies to achieve sustainable development. Practices from previous implementation of the concept of green supply chain management have been proved to be able to obtain economic efficiency simultaneously improve environmental performance [3]. Green supply chain management emphasizes manufacturing, storing, transporting and distributing products in a sustainable fashion through taking into consideration of both environmental and social

The research is supported by TARGET Project and EU Northern Periphery and Arctic (NPA) Programme impacts [4]. Therefore, the purpose of green supply chain management not only accounts the economic sustainability of supply chain and logistics activities but also considers the other pillars of sustainable development: environment and society.

Green supply chain activities include assessment of different supply chain strategies (e.g. production, transportation, distribution, warehousing, etc.), minimization of greenhouse gas (GHG) emission, minimization of energy consumption, improvement of recourse utilization, and reduction of waste generation, and improved waste management [4]. This paper focuses on the "greenness" in supply chain network design and planning. Supply chain network planning is one of the most vital strategic decisions and has great impact on the sustainability of a supply chain from the long-term perspective [5], so it is of significance to develop advanced and multicriteria model for decision making of green supply chain network optimization so as to optimally manage both economic efficiency and environmental performance.

The rest of the paper is organized as follows. Section II provides a literature review of previous models. Section III presents the problem definition and mathematical model. Section IV provides a numerical experiment to demonstrate the applicability of the proposed model, and discussion and analysis of the result are also given in this section. Section V concludes the paper.

\section{LITERATURE REVIEW}

Green supply chain network optimization has become an interesting topic for both academicians and practitioners during the past two decades, and a great number of researches have already been published. This paper summarizes some of the previous studies on this topic, and a comprehensive literature study related to sustainable supply chain and reverse logistics is provided by Govindan et al. [6].

An early attempt is provided by Sarkis [7], in which a theoretical framework for decision making in strategic planning of green supply chain is developed. This paper presents and discusses the fundamental elements for decision analysis of green supply chain management. Sheu et al. [8] propose a linear programming model for the design and planning of an integrated green supply chain network, which aims at minimizing the operational cost of both forward and reverse supply chain. Chiu et al. [2] incorporate the previous 
model with fuzzy set theory and further develop it into a fuzzy multi-objective programming model taking into account of the uncertainties of the input parameters. Yu et al. [5] propose a multi-objective programming for green supply chain network optimization in order to enhance the competitiveness and sustainability of enterprises in sparsely populated areas, and the model aims to simultaneously balance the supply chain operational cost and GHG emissions.

Some researches of green supply chain management target on specific industries. Sheu [9] develop a reveres logistics model for nuclear power system simultaneously taking into consideration of both power generation and supply chain management. Das and Chowdhury [10] formulate a mixed integer programming for reverse network design of product returns. Chien and Shih [11] adopt green supply chain management concept and practice in electrical and electronic industry in Taiwan, and organizational performance of the implementation is also discussed in this paper. Green supply chain management problems in electrical and electronic industry are also focused by $\mathrm{Hsu}$ and $\mathrm{Hu}$ [12]. Pati et al. [13] propose a multi-objective mixed integer programming model for supply chain network design of wastepaper recycling system. The model aims at simultaneously achieve three objectives: minimization of logistics operational cost, improvement of product quality, and improvement of environmental performance. Capraz et al. [14] develop a mathematical model for operational strategy and optimal biding price for waste-to-energy (WTE) facility in a reverse logistics system. Yu et al. [15] formulate a multi-objective linear programming model for sustainable management of reverse supply chain system of municipal solid waste (MSW), and the model aims to balance the system operational cost, GHG emissions from the transportation of waste, and the negative environmental impact imposed to local residences.

A bi-objective mathematical model for green supply chain network design is developed by Wang et al. [1]. The model aims to balances the supply chain operational cost and carbon emission in an optimal fashion, and several sensitivity analyses are also given in this paper in order to test the overall system performance with respect to the change of critical parameters. Rezaee et al. [16] formulate a stochastic programming for green supply chain network planning, which considers the uncertainties related to the customer demand and carbon price. Jakhar [17] proposes a comprehensive decision model for selecting partners and allocating resources in a green supply chain, which employs and combines structural equation modeling, multi-objective programming, and analytical hierarchy process for qualitative and quantitative analysis. Shi et al. [18] develop a supplier evaluation and selection system based upon systematic data envelopment method for green supply chain management.

This paper presents an alternative method to formulate the green supply chain network aiming at simultaneously taking into consideration of both economic efficiency and $\mathrm{CO}_{2}$ emission, and a numerical experiment is also given to show the application of the proposed model. The "cost/ $\mathrm{CO}_{2}$ reduction efficiency" is highlighted and discussed in the numerical experiment, and the cost effectiveness for improving the environmental performance of green supply chain is thoroughly discussed in this paper, which is not mentioned in previous literature, however, this is of significant importance for decision making in strategic planning of green supply chain management, so this work tries to fill the literature gap and presents new result in green supply chain management.

\section{PROBLEM DEFINITION AND MODELING}

\section{A. Problem definition}

In this paper, a general supply chain network with four levels of entities is presented, which includes supplier, production plant, distribution center and customer, as shown in Fig.1. There are three types of flows in a supply chain, namely, material flow, information flow and capital flow [19]. The direction of material flow is usually from raw material suppliers, via production plants and distribution centers, towards end customers, while the information and capital flow is totally opposite from end customers towards raw material suppliers. Supply chain network design aims at, through facility location and transportation planning, managing the three types of flows in an efficient and effective fashion so as to enhance the competitiveness of the supply chain.

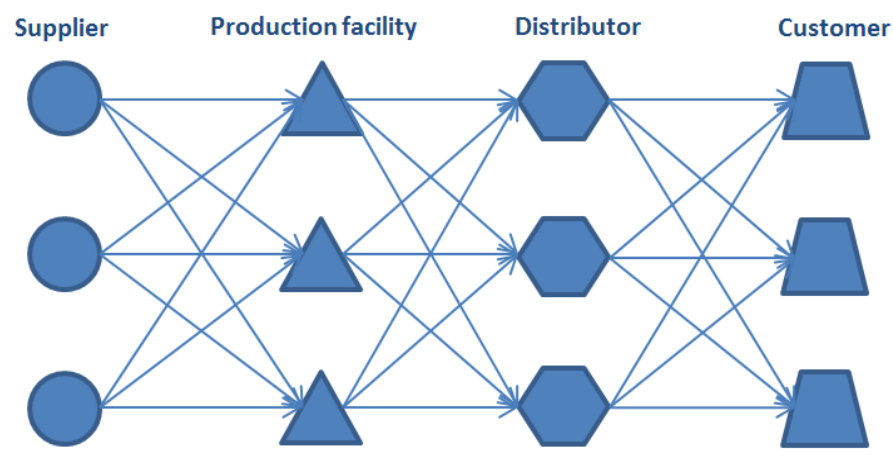

Fig. 1. Supply chain network.

Comparing with traditional supply chain network planning which primarily focuses on maximization of profitability, green supply chain management, however, emphasizes both economic efficiency and environmental sustainability. Based upon the requirement of green supply chain network design, the model consists of two objectives:

1) Supply chain operational cost: The cost for operating supply chain activities, and it includes facility cost and transportation cost.

2) $\mathrm{CO}_{2}$ emission: The $\mathrm{CO}_{2}$ emission from supply chain operations, and it is contributed by facility operations and transportation.

\section{B. Mathematical model}

The mathematical model aims at determining the supply chain network configuration in terms of facility selection and transportation planning, through which the trade-off between supply chain operational cost and $\mathrm{CO}_{2}$ emission is optimized. In this section, the parameters and decision variables are first defined as follows: 


\begin{tabular}{|c|c|}
\hline \multicolumn{2}{|l|}{ Parameters: } \\
\hline$i, I$ & Set of customers \\
\hline$j, J$ & Set of candidate locations of production plant \\
\hline$k, K$ & $\begin{array}{l}\text { Set of candidate locations of distribution } \\
\text { center }\end{array}$ \\
\hline$l, L$ & Set of markets \\
\hline$S_{l}$ & Customer demand of market $l$ \\
\hline$V X_{j}, V X_{k}$ & $\begin{array}{l}\text { Fixed facility cost of production plant } j \text { and } \\
\text { distribution center } k\end{array}$ \\
\hline$V_{j}, V_{k}$ & $\begin{array}{l}\text { Variable processing or storage cost at } \\
\text { production plant } j \text { and distribution center } k\end{array}$ \\
\hline$F_{i j}, F_{j k}, F_{k l}$ & $\begin{array}{l}\text { Cost for transporting one unit product } \\
\text { between } i \text { and } j \text {, between } j \text { and } k \text {, and between } \\
k \text { and } l\end{array}$ \\
\hline$C_{j}$ & $\begin{array}{l}\mathrm{CO}_{2} \text { emission for producing one unit product } \\
\text { at production plant } j\end{array}$ \\
\hline$q_{i j}, q_{j k}, q_{k l}$ & $\begin{array}{l}\mathrm{CO}_{2} \text { emission for transporting one unit } \\
\text { product between } i \text { and } j \text {, between } j \text { and } k \text {, and } \\
\text { between } k \text { and } l\end{array}$ \\
\hline$X_{j}, X_{k}$ & $\begin{array}{l}\text { Capacity of production plant } j \text { and } \\
\text { distribution center } k\end{array}$ \\
\hline \multicolumn{2}{|l|}{ Variables } \\
\hline$\tau_{j}, \tau_{k}$ & $\begin{array}{l}\text { Binary decision variable determining if a } \\
\text { production plant } j \text { or distribution center } k \text { is } \\
\text { open at respective candidate location }\end{array}$ \\
\hline$a_{j}, a_{k}$ & $\begin{array}{l}\text { Produced or stored amount at production } \\
\text { plant } j \text { and distribution center } k\end{array}$ \\
\hline$a_{i j}, a_{j k}, a_{k l}$ & $\begin{array}{l}\text { Transported amount between } i \text { and } j \text {, between } \\
j \text { and } k \text {, and between } k \text { and } l\end{array}$ \\
\hline CFL & Facility cost \\
\hline CTV & Transportation cost \\
\hline EFL & $\mathrm{CO} 2$ emission of facility \\
\hline ETV & $\mathrm{CO} 2$ emission of transportation \\
\hline \multicolumn{2}{|c|}{ Derivational variable } \\
\hline$d_{\text {cost }}^{+}, d_{\text {cost }}^{-}$ & $\begin{array}{l}\text { Positive and negative deviation of the supply } \\
\text { chain operational cost goal function }\end{array}$ \\
\hline$d_{\mathrm{CO} 2}^{+}, d_{\mathrm{CO} 2}^{-}$ & $\begin{array}{l}\text { Positive and negative deviation of the } \mathrm{CO}_{2} \\
\text { emission goal function }\end{array}$ \\
\hline
\end{tabular}

The model is formulated as a goal programming which minimizes the deviation from the weighted goal, and Eq. (1) presents the objective function of the model. Herein, $d_{\text {cost }}^{+}$and $d_{\mathrm{CO} 2}^{+}$are the deviation of supply chain operational cost and
$\mathrm{CO}_{2}$ emission, and $\vartheta_{\text {cost }}$ and $\vartheta_{\mathrm{CO} 2}$ represent the weight of respective objectives.

$$
\text { Minimize } \vartheta_{\text {cost }} d_{\text {cost }}^{+}+\vartheta_{\mathrm{CO} 2} d_{C O 2}^{+}
$$

It is noted that supply chain operational cost and $\mathrm{CO}_{2}$ emission are measured by different units, so the objective function is normalized through Eq. (2). Herein, represent the target value of respective goal functions.

$$
\text { Minimize } \vartheta_{\text {cost }} \frac{d_{\text {cost }}^{+}}{\operatorname{Goal}(\text { cost })}+\vartheta_{\text {CO2 }} \frac{d_{\text {CO2 }}^{+}}{\operatorname{Goal}(\operatorname{CO} 2)}
$$

The goal function of supply chain operational cost is presented in Eq. (3). Two types of cost related to supply chain activities are considered in this model: facility cost and transportation cost. Eq. (4) calculates the facility cost, and it includes fixed operational cost and variable processing cost. Eq. (5) calculates the transportation cost of raw materials and finished products.

$$
\begin{gathered}
\text { Cost }=\text { CFL }+ \text { CTV }+\left(d_{\text {cost }}^{+}-d_{\text {cost }}^{-}\right) \\
\mathrm{CFL}=\sum_{j \in j}\left(V X_{j} \tau_{j}+V_{j} a_{j}\right)+\sum_{k \in K}\left(V X_{k} \tau_{k}+V_{k} a_{k}\right) \\
\mathrm{CTV}=\sum_{i \in I} \sum_{j \in J} F_{i j} a_{i j}+\sum_{j \in J} \sum_{k \in K} F_{j k} a_{j k}+\sum_{k \in K} \sum_{l \in L} F_{k l} a_{k l}
\end{gathered}
$$

Eq. (6) illustrates the goal function of $\mathrm{CO}_{2}$ emission of the supply chain. The $\mathrm{CO}_{2}$ emission from a supply is mainly contributed by two sources: production and transportation, and the calculation of those two types of $\mathrm{CO}_{2}$ emission is given in Eq. (7) and Eq. (8).

$$
\begin{gathered}
\mathrm{CO} 2=\mathrm{EFL}+\mathrm{ETV}+\left(d_{\mathrm{CO} 2}^{+}-d_{\mathrm{CO} 2}^{-}\right) \\
\mathrm{EFL}=\sum_{j \in j} C_{j} a_{j} \tau_{j} \\
\mathrm{ETV}=\sum_{i \in I} \sum_{j \in J} q_{i j} a_{i j}+\sum_{j \in J} \sum_{k \in K} q_{j k} a_{j k}+\sum_{k \in K} \sum_{l \in L} q_{k l} a_{k l}
\end{gathered}
$$

Several constraints are also formulated in the model in order to fulfill different requirements, which are illustrated in Eqs. (9)-(16).

$$
\begin{gathered}
\sum_{i \in I} a_{i j}=a_{j}=\sum_{k \in K} a_{j k}, \forall j \in J \\
\sum_{j \in J} a_{j k}=a_{k}=\sum_{l \in L} a_{k l}, \forall k \in K \\
\sum_{k \in K} a_{k l}=S_{l}, \forall l \in L
\end{gathered}
$$


Eqs. (9) and (10) restrict the input flow equals to the output flow at production plant and distribution center. Eq. (11) ensures the customer demand is satisfied at each market.

$$
\begin{gathered}
a_{i j} \leq \tau_{j} P, \forall i \in I, j \in J \\
a_{j k} \leq \tau_{j} \tau_{k} P, \forall j \in J, k \in K \\
a_{k l} \leq \tau_{k} P, \forall k \in K, l \in L
\end{gathered}
$$

Eqs. (12), (13) and (14) guarantee that the transportation of raw materials or finished products cannot exist if the corresponding facilities are not selected to open production plant or distribution center. Herein, $P$ is an infinitely large positive number.

$$
\begin{gathered}
a_{j} \leq X_{j} \tau_{j}, \forall j \in J \\
a_{k} \leq X_{k} \tau_{k}, \forall k \in K
\end{gathered}
$$

Eqs. (15) and (16) restrict that the quantity processed and stored at production plants and distribution centers cannot exceed their respective capacities.

$$
\begin{gathered}
\tau_{j}, \tau_{k} \in\{0,1\}, \forall j \in J, k \in K \\
a_{j}, a_{k}, a_{i j}, a_{j k}, a_{k l} \geq 0, \forall i \in I, j \in J, k \in K, l \in L \\
d_{\text {cost }}^{+}, d_{\text {cost }}^{-}, d_{C O 2}^{+}, d_{C O 2}^{-} \geq 0
\end{gathered}
$$

Eq. (17) is the requirement of binary variable in facility selection. Eq. (18) is the non-negative requirement for decision variables in transportation planning. Eq. (19) is the nonnegative requirement for derivative variables.

\section{NUMERICAL EXPERIMENT}

The numerical experiment aims at illustrating the application of the proposed model. The example includes ten customers, six candidate locations for production plant, six candidate locations for distribution center, and eight markets. The corresponding parameters of the candidate locations of production plant are illustrated in Tables I.

TABLE I. PARAMETERS OF CANDIDATE LOCATIONS OF PRODUCTION PLANT

\begin{tabular}{|c|c|c|c|c|c|c|}
\hline \multirow{2}{*}{$\begin{array}{c}\text { Param } \\
\text { eter }\end{array}$} & \multicolumn{7}{|c|}{ Candidate $\boldsymbol{j}$} \\
\cline { 2 - 7 } & $\boldsymbol{j} \mathbf{1}$ & $\boldsymbol{j} \mathbf{2}$ & $\boldsymbol{j} \mathbf{3}$ & $\boldsymbol{j} 4$ & $\boldsymbol{j} 5$ & $\boldsymbol{j} \boldsymbol{6}$ \\
\hline $\boldsymbol{V} \boldsymbol{X}_{\boldsymbol{j}}$ & 650321 & 611467 & 758040 & 643940 & 681239 & 707462 \\
\hline $\boldsymbol{V}_{\boldsymbol{j}}$ & 328 & 481 & 528 & 541 & 437 & 526 \\
\hline $\boldsymbol{X}_{\boldsymbol{j}}$ & 12601 & 21670 & 29190 & 25593 & 25806 & 17225 \\
\hline $\boldsymbol{C}_{\boldsymbol{j}}$ & 305 & 208 & 190 & 185 & 229 & 191 \\
\hline
\end{tabular}

The relevant parameters are generated as random numbers within a given interval. Furthermore, the units of parameters are not given in a specific form in this example. It is noted that the unit processing cost is inversely related to the $\mathrm{CO}_{2}$ emission at production plant, because the reduction of $\mathrm{CO}_{2}$ emission and improvement of environmental performance require more efforts and advanced technologies, which usually leads to higher investment [1]. In this example, Eq. (20) is applied to generate the numerical value of $\mathrm{CO}_{2}$ emission per unit product at each production plant with respect to the variable processing cost. In Eq. (20), the random integer is also generated within a given interval which reflects the interactions between processing cost and $\mathrm{CO}_{2}$ emission.

$$
C_{j}=\frac{1}{\text { Random Integer }} V_{j}
$$

TABLE II. PARAMETERS OF CANDIDATE LOCATIONS OF DISTRIBUTION CENTER

\begin{tabular}{|c|c|c|c|c|c|c|}
\hline \multirow{2}{*}{$\begin{array}{c}\text { Param } \\
\text { eter }\end{array}$} & \multicolumn{7}{|c|}{ Candidate $\boldsymbol{k}$} \\
\cline { 2 - 7 } & $\boldsymbol{j 1}$ & $\boldsymbol{j} \mathbf{2}$ & $\boldsymbol{j 3}$ & $\boldsymbol{j 4}$ & $\boldsymbol{j 5}$ & $\boldsymbol{j} \boldsymbol{6}$ \\
\hline $\boldsymbol{V} \boldsymbol{X}_{\boldsymbol{k}}$ & 282776 & 245907 & 261514 & 413161 & 315487 & 256699 \\
\hline $\boldsymbol{V}_{\boldsymbol{k}}$ & 52 & 68 & 50 & 62 & 60 & 74 \\
\hline $\boldsymbol{X}_{\boldsymbol{k}}$ & 29294 & 30520 & 43451 & 39191 & 27372 & 29654 \\
\hline
\end{tabular}

Table II presents the relevant parameters of candidate locations of distribution center. The unit transportation cost and

\begin{tabular}{|c|c|c|c|c|c|c|}
\hline \multirow{2}{*}{$\begin{array}{c}\text { Custo } \\
\text { mer }\end{array}$} & \multicolumn{6}{|c|}{ Candidate $\boldsymbol{j}$} \\
\hline & $j 1$ & $j 2$ & $j 3$ & $j 4$ & j5 & j6 \\
\hline$i 1$ & 74 & 94 & 104 & 118 & 101 & 84 \\
\hline$i 2$ & 70 & 106 & 93 & 110 & 74 & 118 \\
\hline$i 3$ & 93 & 90 & 94 & 102 & 76 & 92 \\
\hline i4 & 119 & 102 & 107 & 79 & 100 & 117 \\
\hline$i 5$ & 86 & 116 & 95 & 95 & 99 & 80 \\
\hline i6 & 105 & 86 & 87 & 91 & 82 & 111 \\
\hline$i 7$ & 106 & 88 & 87 & 95 & 88 & 93 \\
\hline$i 8$ & 111 & 95 & 95 & 120 & 85 & 119 \\
\hline i9 & 96 & 120 & 113 & 79 & 94 & 97 \\
\hline i10 & 83 & 82 & 120 & 94 & 91 & 77 \\
\hline
\end{tabular}
$\mathrm{CO}_{2}$ emission between customers and production plants, between production plants and distribution centers, and between distribution centers and markets are illustrated in Tables III, IV, V, VI, VII and VIII, respectively. The cost and $\mathrm{CO}_{2}$ emission related to transportation are directly related to the distance traveled.

TABLE III. UNIT TRANSPORTATION COST BETWEEN CUSTOMERS AND PRODUCTION PLANTS

TABLE IV. $\mathrm{CO}_{2}$ EMISSION BETWEEN CUSTOMERS AND PRODUCTION PLANTS

\begin{tabular}{|c|c|c|c|c|c|c|}
\hline \multirow{2}{*}{$\begin{array}{c}\text { Custo } \\
\text { mer }\end{array}$} & \multicolumn{7}{|c|}{ Candidate $\boldsymbol{j}$} \\
\cline { 2 - 7 } & $\boldsymbol{j 1}$ & $\boldsymbol{j} \mathbf{2}$ & $\boldsymbol{j 3}$ & $\boldsymbol{j} \mathbf{4}$ & $\boldsymbol{j} \mathbf{5}$ & $\boldsymbol{j} \boldsymbol{6}$ \\
\hline $\boldsymbol{i 1}$ & 47 & 47 & 73 & 59 & 101 & 47 \\
\hline $\boldsymbol{i 2}$ & 62 & 59 & 51 & 28 & 74 & 83 \\
\hline $\boldsymbol{i 3}$ & 24 & 70 & 57 & 38 & 29 & 72 \\
\hline $\boldsymbol{i 4}$ & 76 & 47 & 60 & 58 & 100 & 32 \\
\hline $\boldsymbol{i 5}$ & 51 & 68 & 29 & 95 & 66 & 27 \\
\hline $\boldsymbol{i 6}$ & 53 & 52 & 49 & 31 & 35 & 111 \\
\hline $\boldsymbol{i 7}$ & 75 & 36 & 51 & 43 & 30 & 60 \\
\hline $\boldsymbol{i 8}$ & 61 & 61 & 70 & 60 & 22 & 33 \\
\hline $\boldsymbol{i 9}$ & 48 & 77 & 57 & 62 & 84 & 65 \\
\hline $\boldsymbol{i 1 0}$ & 56 & 25 & 94 & 60 & 73 & 54 \\
\hline
\end{tabular}


TABLE V. Unit Transportation Cost Between Production Plant AND DISTRIBUTION CENTER

\begin{tabular}{|c|c|c|c|c|c|c|}
\hline \multirow{2}{*}{$\begin{array}{c}\text { Produc } \\
\text { tion }\end{array}$} & \multicolumn{7}{|c|}{ Candidate $\boldsymbol{k}$} \\
\cline { 2 - 7 } & $\boldsymbol{k} \mathbf{1}$ & $\boldsymbol{k} \mathbf{2}$ & $\boldsymbol{k 3}$ & $\boldsymbol{k 4}$ & $\boldsymbol{k 5}$ & $\boldsymbol{k} \boldsymbol{6}$ \\
\hline $\boldsymbol{j} \mathbf{1}$ & 147 & 140 & 147 & 128 & 107 & 90 \\
\hline $\boldsymbol{j} \mathbf{2}$ & 124 & 123 & 149 & 110 & 137 & 140 \\
\hline $\boldsymbol{j} \mathbf{3}$ & 109 & 142 & 147 & 134 & 104 & 125 \\
\hline $\boldsymbol{j} \mathbf{4}$ & 111 & 93 & 91 & 111 & 128 & 123 \\
\hline $\boldsymbol{j} \mathbf{5}$ & 93 & 93 & 145 & 126 & 107 & 126 \\
\hline $\boldsymbol{j} \mathbf{6}$ & 108 & 135 & 128 & 103 & 119 & 93 \\
\hline
\end{tabular}

TABLE VI. $\quad \mathrm{CO}_{2}$ EMISSION BETWEEN PRODUCTION PLANT AND DISTRIBUTION CENTER

\begin{tabular}{|c|c|c|c|c|c|c|}
\hline \multirow{2}{*}{$\begin{array}{c}\text { Produc } \\
\text { tion }\end{array}$} & \multicolumn{7}{|c|}{ Candidate $\boldsymbol{k}$} \\
\cline { 2 - 7 } & $\boldsymbol{k 1}$ & $\boldsymbol{k 2}$ & $\boldsymbol{k 3}$ & $\boldsymbol{k 4}$ & $\boldsymbol{k 5}$ & $\boldsymbol{k} \boldsymbol{6}$ \\
\hline $\boldsymbol{j} \mathbf{1}$ & 92 & 59 & 111 & 64 & 39 & 53 \\
\hline $\boldsymbol{j} \mathbf{2}$ & 46 & 31 & 109 & 50 & 137 & 77 \\
\hline $\boldsymbol{j 3}$ & 37 & 60 & 103 & 56 & 38 & 38 \\
\hline $\boldsymbol{j 4}$ & 87 & 51 & 46 & 31 & 59 & 62 \\
\hline $\boldsymbol{j} \mathbf{5}$ & 52 & 75 & 40 & 79 & 81 & 112 \\
\hline $\boldsymbol{j 6}$ & 72 & 119 & 57 & 92 & 53 & 35 \\
\hline
\end{tabular}

TABLE VII. UNIT TRANSPORTATION COST BETWEEN DISTRIBUTION CENTER AND MARKET

\begin{tabular}{|c|c|c|c|c|c|c|c|c|}
\hline \multirow{2}{*}{$\begin{array}{c}\text { Dist } \\
\text { ribu } \\
\text { tion }\end{array}$} & \multicolumn{10}{|c|}{ Market $\boldsymbol{l}$} \\
\cline { 2 - 9 } $\boldsymbol{k 1}$ & 95 & 89 & 89 & 79 & 92 & 92 & 83 & 80 \\
\hline $\boldsymbol{k 2}$ & 75 & 84 & 85 & 70 & 94 & 82 & 75 & 87 \\
\hline $\boldsymbol{k 3}$ & 70 & 93 & 82 & 75 & 99 & 75 & 72 & 87 \\
\hline $\boldsymbol{k 4}$ & 71 & 77 & 71 & 98 & 90 & 84 & 95 & 74 \\
\hline $\boldsymbol{k 5}$ & 89 & 79 & 72 & 72 & 99 & 86 & 76 & 99 \\
\hline $\boldsymbol{k 6}$ & 79 & 95 & 95 & 97 & 86 & 97 & 97 & 78 \\
\hline
\end{tabular}

TABLE VIII. $\quad \mathrm{CO}_{2}$ EMISSION BETWEEN DISTRIBUTION CENTER AND MARKET

\begin{tabular}{|c|c|c|c|c|c|c|c|c|}
\hline $\begin{array}{c}\text { Dist } \\
\text { ribu } \\
\text { tion }\end{array}$ & \multicolumn{10}{|c|}{ Market $\boldsymbol{l}$} \\
\cline { 2 - 9 } & $\boldsymbol{l}$ & $\boldsymbol{l} \boldsymbol{2}$ & $\boldsymbol{l 3}$ & $\boldsymbol{l 4}$ & $\boldsymbol{l 5}$ & $\boldsymbol{l 6}$ & $\boldsymbol{l 7}$ & $\boldsymbol{l} \boldsymbol{8}$ \\
\hline $\boldsymbol{k} \boldsymbol{1}$ & 26 & 23 & 45 & 60 & 74 & 62 & 28 & 30 \\
\hline $\boldsymbol{k} \boldsymbol{2}$ & 75 & 68 & 57 & 44 & 60 & 82 & 38 & 44 \\
\hline $\boldsymbol{k 3}$ & 56 & 62 & 28 & 75 & 70 & 66 & 58 & 56 \\
\hline $\boldsymbol{k 4}$ & 40 & 54 & 40 & 86 & 80 & 35 & 32 & 30 \\
\hline $\boldsymbol{k 5}$ & 80 & 40 & 24 & 20 & 30 & 29 & 35 & 75 \\
\hline $\boldsymbol{k} \boldsymbol{6}$ & 70 & 48 & 36 & 73 & 35 & 62 & 27 & 32 \\
\hline
\end{tabular}

The customer demands of each market are 2081, 1696, 4089, 4444, 2757, 4486, 4321 and 3760, respectively. After all the parameters are set, the mathematical programming is solved using LINGO optimization solver. The goal values of supply chain operational cost and $\mathrm{CO}_{2}$ emission are first calculated through resolving each individual goal function. The goal of supply chain operational cost is 21166290 , and the goal of $\mathrm{CO}_{2}$ emission equals to 7705712. The results of three scenarios with different distribution of weights to the goal of supply chain operational cost and the goal of $\mathrm{CO}_{2}$ emission is presented in Tables IX.
TABLE IX. OPTIMAL SOLUtions OF TESTED SCENARIOS

\begin{tabular}{|c|c|c|c|}
\hline Scenario & \multicolumn{3}{|c|}{$\begin{array}{c}\text { Goal value: } \\
\text { Goal supply chain operational cost }=21166290 \\
\mathrm{CO}_{2} \text { emission }=7705712\end{array}$} \\
\hline \multirow{9}{*}{1} & \multirow{2}{*}{ Weight } & $\vartheta_{\text {cost }}$ & 0.7 \\
\hline & & $\vartheta_{\mathrm{CO} 2}$ & 0.3 \\
\hline & \multirow{2}{*}{ Deviation } & $d_{\text {cost }}^{+}$ & 399810 \\
\hline & & $d_{C O 2}^{+}$ & 2385088 \\
\hline & \multirow{2}{*}{ Facility } & $j$ & $j 1, j 5$ \\
\hline & & $k$ & $k 1, k 5$ \\
\hline & \multirow{3}{*}{$\begin{array}{l}\text { Transportation } \\
\text { plan }\end{array}$} & $a_{i j}$ & $a_{31}=12601, a_{35}=15033$ \\
\hline & & $a_{j k}$ & $a_{15}=12601, a_{51}=15033$ \\
\hline & & $a_{k l}$ & $\begin{array}{c}a_{11}=2081, a_{12}=1696, a_{13}=3175, \\
a_{17}=4321, a_{18}=3760, a_{53}=914, \\
a_{54}=4444, a_{55}=2757, a_{56}=4486\end{array}$ \\
\hline \multirow{9}{*}{2} & \multirow{2}{*}{ Weight } & $\vartheta_{\text {cost }}$ & 0.5 \\
\hline & & $\vartheta_{\mathrm{CO} 2}$ & 0.5 \\
\hline & \multirow{2}{*}{ Deviation } & $d_{\text {cost }}^{+}$ & 4183590 \\
\hline & & $d_{C O 2}^{+}$ & 111090 \\
\hline & \multirow{2}{*}{ Facility } & $j$ & $j 3$ \\
\hline & & $k$ & $k 1, k 5$ \\
\hline & \multirow{3}{*}{$\begin{array}{l}\text { Transportation } \\
\text { plan }\end{array}$} & $a_{i j}$ & $a_{53}=27634$ \\
\hline & & $a_{j k}$ & $a_{31}=11858, a_{35}=15776$ \\
\hline & & $a_{k l}$ & $\begin{array}{c}a_{11}=2081, a_{12}=1696, a_{17}=4321, \\
a_{18}=3760, a_{53}=4089, a_{54}=4444, \\
a_{55}=2757, a_{56}=4486\end{array}$ \\
\hline \multirow{9}{*}{3} & \multirow{2}{*}{ Weight } & $\boldsymbol{\vartheta}_{\text {cost }}$ & 0.3 \\
\hline & & $\vartheta_{\mathrm{CO} 2}$ & 0.7 \\
\hline & \multirow{2}{*}{ Deviation } & $d_{\text {cost }}^{+}$ & 4183590 \\
\hline & & $d_{C O 2}^{+}$ & 111090 \\
\hline & \multirow{2}{*}{ Facility } & $j$ & $j 3$ \\
\hline & & $k$ & $k 1, k 5$ \\
\hline & \multirow{3}{*}{$\begin{array}{l}\text { Transportation } \\
\text { plan }\end{array}$} & $a_{i j}$ & $a_{53}=27634$ \\
\hline & & $a_{j k}$ & $a_{31}=11858, a_{35}=15776$ \\
\hline & & $a_{k l}$ & $\begin{array}{c}a_{11}=2081, a_{12}=1696, a_{17}=4321, \\
a_{18}=3760, a_{53}=4089, a_{54}=4444, \\
a_{55}=2757, a_{56}=4486\end{array}$ \\
\hline
\end{tabular}

The cost deviation in scenario 1 is the smallest compared with the other two tested scenarios, but the $\mathrm{CO}_{2}$ emission is the highest one either. This illustrates that an economical efficient supply chain cannot be, at the same time, a low $\mathrm{CO}_{2}$ emission and environmentally sustainable system. In scenario 2, the importance of the goal of $\mathrm{CO}_{2}$ emission increases, so the deviation of $\mathrm{CO}_{2}$ emission decreases, while the deviation of supply chain operational cost increases. The location selection and transportation planning in scenario 3 are the same as that in scenario 2, which implies the change of corresponding weighs of the goals of supply chain operational cost and $\mathrm{CO}_{2}$ emission may not always alter the supply chain configuration and overall performance.

Fig. 2 shows the change of deviation of supply chain operational cost as well as its impact on the deviation of $\mathrm{CO}_{2}$ emission. As shown in the figure, the supply chain operational cost reduced if more importance is given to it, while the $\mathrm{CO}_{2}$ emission of the supply chain increases accordingly. It is also note that the curve becomes more flat with the increase of deviation of supply chain operational cost. This reveals the cost effectiveness for reducing $\mathrm{CO}_{2}$ emission of a supply chain. 
When the $\mathrm{CO}_{2}$ emission is taking into account in decision making and is given a small weight, the $\mathrm{CO}_{2}$ emission can be significantly reduced by $15 \%$ with the increase in supply chain operational cost by less than $2 \%$, and this shows that the investment is most effective at this stage. However, with the increase of the importance of $\mathrm{CO}_{2}$ emission in supply chain design, the cost effectiveness for improving environmental performance will reduce gradually. This result has significant managerial meaning for decision making of the network design of green supply chain.

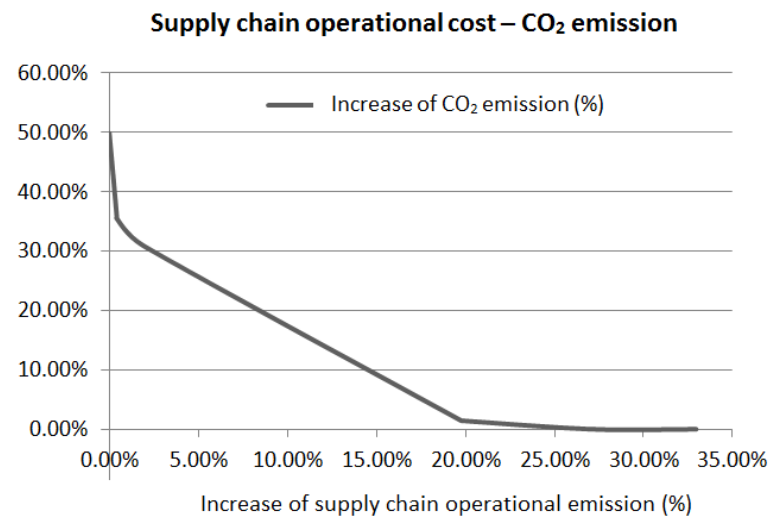

Fig. 2. Sensitivity analysis of supply chain operational cost and $\mathrm{CO}_{2}$ emission.

\section{CONCLUDING REMARKS}

This paper has presented a goal programming approach for green supply chain network design and optimization. The mathematical model accounts both supply chain operational cost and environmental sustainability in location selection and transportation planning of green supply chain. The environmental sustainability of supply chain activities is measured by $\mathrm{CO}_{2}$ emission in this study. The result of the numerical experiment shows the trade-off between supply chain operational cost and $\mathrm{CO}_{2}$ emission, and more efforts and investment should be spent in order to reduce the $\mathrm{CO}_{2}$ emission and to improve the environmental sustainability of a supply chain. Furthermore, the cost effectiveness and efficiency for improving environmental sustainability is also presented in this paper, which has great meaning in decision making of green supply chain planning.

The model can be further extended in several aspects, such as the inclusion of reverse logistics activities, uncertain customer demands and supplier capacities, responsiveness goal of the supply chain, and integration with geographical information system (GIS). Besides, decision making of shortterm operational planning, i.e., inventory management, route planning, etc., may also be included for the further development of the model.

\section{ACKNOWLEDGMENT}

The authors would like to express their gratitude to the TARGET Project and EU Northern Periphery and Arctic (NPA) Programme.

\section{REFERENCES}

[1] F. Wang, X. Lai, and N. Shi, "A multi-objective optimization for green supply chain network design,” Decision Support Systems, vol. 51, 2001, pp. 262-269.

[2] C.Y. Chiu, Y. Lin, and M.F. Yang, "Applying fuzzy multiobjective integrated logistics model to green supply chain problems," Journal of Applied Mathematics, vol. 2014, 2014, doi: http://dx.doi.org/10.1155/2014/767095

[3] S. Ubeda, F.J. Arcelus, and J. Faulin, "Green logistics at Eroski: A case study," International Journal of Production Economics, vol. 131(1), 2011, pp. 44-51.

[4] A. Sbihi, and R.W. Eglese, "Combinatorial optimization and green logistics," 4OR, vol. 5, 2007, pp. 99-116.

[5] H, Yu, W.D. Solvang, and C. Chen, "A green supply chain network design model for enhancing competitiveness and sustainability of companies in high north arctic regions," International Journal of Energy and Environment, vol. 5(4), 2014, pp. 403-418.

[6] K. Govindan, H. Soleimani, and D. Kannan, "Reverse logistics and closed-loop supply chain: A comprehensive review to explore the future," European Journal of Operational Research, vol. 240, 2015, pp. 603-626.

[7] J. Sarkis, "A strategic decision framework for green supply chain management," Journal of Cleaner Production, vol. 11(4), 2003, pp. 397409.

[8] J.B. Sheu, Y.H. Chou, and C.C. Hu, "An integrated logistics operational model for green-supply chain management," Transportation Research Part E, vol. 41(4), 2005, pp. 287-313.

[9] J.B. Sheu, "Green supply chain management, reverse logistics and nuclear power generation," Transportation Research Part E, vol. 44(1), 2008, pp. 19-46.

[10] K. Das, and A.H. Chowdhury, "Designing a reverse logistics network for optimal collection, recovery and quality-based product-mix planning," International Journal of Production Economics, vol. 135(1), 2012, pp. 209-221.

[11] M.K. Chien, and L.H. Shih, "An empirical study of the implementation of green supply chain management practices in the electrical and electronic industry and their relation to organizational performance," International Journal of Environmental Science and Technology, vol. 4(3), 2007, pp. 383-394.

[12] C.W. Hsu, and A.H. Hu, "Green supply chain management in the electronic industry," International Journal of Environmental Science and Technology, vol. 5(2), 2008, pp. 205-216.

[13] R.K. Pati, P. Vrat, and P. Kumar, "A goal programming model for paper recycling system,” Omega, vol. 36, 2008, pp: 405-417.

[14] O. Capraz, O. Polat, and A. Gungor, "Planning of waste electrical and electronic equipment (WEEE) recycling facilities: MILP modelling and case study investigation," Flexible Services and Manufacturing Journal, vol. 27, 2015, pp. 479-508.

[15] H. Yu, W.D. Solvang, S. Yuan, and Y. Yang, "A decision aided system for sustainable waste management," Intelligent Decision Technologies, vol. 9(1), 2015, pp. 29-40.

[16] A. Rezaee, F. Dehghanian, B. Fahimnia, and B. Beamon, "Green supply chain network design with stochastic demand and carbon price," Annals of Operational Research, 2015, doi: 10.1007/s10479-015-1936-z

[17] S.K. Jakhar, "Designing the green supply chain performance optimization model," Global Journal of Flexible Systems Management, vol. 15(3), 2014, pp. 235-259.

[18] P. Shi, B. Yan, S. Shi, and C. Ke, "A decision support system to select suppliers for a sustainable supply chain based on a systematic DEA approach," Information Technology and Management, vol. 16(1), 2015, pp. 39-49.

[19] S. Chopra, and P. Meindl, Supply Chain Management: Strategy, Planning, and Operation, $6^{\text {th }}$ Edition, Pearson, 2014.

[20] H. Yu, and W.D. Solvang, "A general reverse logistics network design model for product reuse and recycling with environmental considerations," International Journal of Advanced Manufacturing Technology, 2016. doi: 10.1007/s00170-016-8612-6 